\title{
ARTICLE
}

\section{Insecticidal activity of isolated essential oils from three me- dicinal plants on the biological control agent, Habrobracon hebetor Say (Hymenoptera: Braconidae)}

\author{
Mohammad Asadi, Hooshang Rafiee-Dastjerdi*, Gadir Nouri-Ganbalani, Bahram Naseri, \\ Mahdi Hassanpour
}

Department of Plant Protection, Faculty of Agriculture and Natural Resources, University of Mohaghegh Ardabili, Ardabil, Iran

\begin{abstract}
The effects of Allium sativum L. (Alliaceae), Piper nigrum L. (Piperaceae) and Glycyrrhiza glabra L. (Fabaceae) essential oils were investigated on the biological control agent, Habrobracon hebetor Say. The female wasps of $H$. hebetor were treated by $\mathrm{LC}_{30}$ concentrations of the tested essential oils for $24 \mathrm{~h}$ and their demography was investigated. Results indicated that the adult longevity, survival, fecundity, fertility, hatch rate, offspring sex ratio and the other demographic parameters negatively were affected by these essential oils. At the same time, our findings indicated that G. glabra essential oil has the less severe effect on $H$. hebetor. Accordingly, G. glabra essential oil seems to be a compatible botanical compound with $H$. hebetor for applying in integrated pest management programs.

Acta Biol Szeged 63(1):63-68 (2019)
\end{abstract}

\author{
KEY WORDS \\ integrated pest management \\ natural enemy \\ plant compounds \\ toxicity \\ ARTICLE INFORMATION \\ Submitted \\ 4 May 2019 \\ Accepted \\ 11 July 2019 \\ *Corresponding author \\ E-mail: hooshangrafiee@gmail.com
}

\section{Introduction}

The synthetic pesticides concern environmental pollution, emergence of resistance in insect pests and negative effects on non-target organisms in agricultural ecosystems (Sagheer et al. 2014; Yazdgerdian et al. 2015; Asadi et al. 2018a). During the last decades, application of various natural compounds were seriously considered for the effective control of insect pests (Mwine et al. 2013; Rafiee-Dastjerdi et al. 2013; Kramer et al. 2016; Asadi et al. 2018a). According to this, the compounds of plant origin including essential oils and extracts have been recommended as natural and effective compounds in integrated pest management (IPM) programs (Koul et al. 2008; Manzoor et al. 2011; Asadi et al. 2018a; Razmjou et al. 2018). The essential oils are a chemically diverse group of volatile plant metabolites (Bakkali et al. 2008; Isman et al. 2008; Rafiee-Dastjerdi et al. 2013). Most of these odor compounds have fumigant, contact, repellent and antifeedant properties and, therefore, they are frequently recommended for control of insect pests due to their high insecticidal activity and low negative effects on non-target organisms (Isman 2000; Yildirim et al. 2011; Rafiee-Dastjerdi et al. 2013; Shiva Parsia and Valizadegan 2015; Asadi et al. 2018a).

Application of any compounds of synthetic or natural origin potentially can have harmful effects on demography of the natural enemies of pests including predators and parasitoids (Stark et al. 2004; Mahmoudvand et al. 2011). The acute toxicity of different compounds on insect populations previously have been investigated in detail, but the sublethal effects of them have not been considered completely (Motazedian et al. 2012; Mwine et al. 2013). The negative sublethal effects can change the demographic parameters and finally will reduce the efficiency of natural enemies for control of their hosts (Croft 1990; Stark and Wennergren 1995; Salerno et al. 2002; Stark and Banks 2003; Desneux et al. 2007; Hamedi et al. 2010 and 2011).

There are several reports describing the harmful effects of some plant essential oils and the other compounds of plant origin on non-target organisms especially on the natural enemies of pests (Abramson et al. 2006; Asadi et al. 2018a). If the application of plant essential oils will be widespread, they can disrupt the biological control agents in IPM programs (Desneux et al. 2007). Accordingly, coapplication of biological control agents with plant-based compounds requires suitable knowledge about their obvious and hidden interactions (Dent 1995; Banks and Stark 1998; Desneux et al. 2007). These researches are defined as demographic toxicology that is a useful tool for understanding the effects of different compounds on populations of different insects and their natural enemies (Walthall and Stark 1996; Stapel et al. 2000; Stark and 
Banks 2003; Desneux et al. 2007).

Habrobracon hebetor Say is one of the important natural enemies of different destructive lepidopteran larvae especially from families Pyralidae and Noctuidae in agricultural crops (Gerling 1971; Youm and Gilstrap 1993; Magro and Parra 2001; Navaei et al. 2002). The projects on the mass rearing of this ectoparasitoid wasp have been started in Iran in different commercial insectariums and it has been released for the control of some invasive lepidopteran pests (Navaei et al. 2002; Ahmadpour 2017). However, little information is available regarding the lethal and sublethal effects of plant essential oils and the other plant compounds on this important ectoparasitoid wasp (Seyyedi 2011; Hashemi et al. 2014; Ahmadpour 2017; Asadi et al. 2018a; Razmjou et al. 2018).

Three medicinal plants were selected for this study, including garlic (A. sativum), black pepper (P. nigrum) and liquorice (G. glabra). It is known from previous studies that they have sufficient amount of essential oil with high insecticidal activity (Koul et al. 2008; Ajayi and Olonisakin 2011; Rafiee-Dastjerdi et al. 2013). In this research we investigated the effects of isolated essential oils from above-mentioned medicinal plants on $H$. hebetor for evaluation the possibility of their integration with this important biocontrol agent in IPM programs.

\section{Materials and Methods}

\section{Essential oils isolation and analysis}

The mature plants of garlic (Allium sativum L., Alliaceae), black pepper (Piper nigrum L., Piperaceae) and liquorice (Glycyrrhiza glabra L., Fabaceae) were collected in different regions of Islam-Abad Gharb city $\left(34.11^{\circ} \mathrm{N}\right.$ and $\left.46.52^{\circ} \mathrm{E}\right)$ (Kermanshah province, Iran) during May to June 2016. The collected plants were dried in shadow conditions under room temperature (approximately $25{ }^{\circ} \mathrm{C}$ ). Parts of the collected plants (bulbs of $A$. sativum, seeds of P. nigrum and leaves of G. glabra) that contained the highest insecticidal activity were considered. Analyses of the isolated essential oils were carried out with a Gas Chromatography-Mass spectroscopy (GC-MS; Agilent, 7890 B) as described earlier (Asadi et al. 2018b). Investigation of fumigant toxicity on the young female wasps of $H$. hebetor (less than $24 \mathrm{~h}$ old) also was carried out as described earlier (Asadi et al. 2018b).

\section{Rearing of biological control agent}

The primitive adult wasps of $H$. hebetor were obtained from a private insectarium (registered name: KeshtGostar Pishgam) in Islam-Abad Gharb city (Kermanshah province, Iran), during 2017. The obtained parasitoids urgently were transferred to laboratory conditions at 25
Table 1. The biological parameters of $H$. hebetor females treated by the isolated essential oils.

\begin{tabular}{llll}
\hline Treatment & $\begin{array}{l}\text { Female longevity } \\
\text { (day) }\end{array}$ & $\begin{array}{l}\text { Daily fecundity } \\
\text { (egg) }\end{array}$ & $\begin{array}{l}\text { Daily fertility } \\
\text { (egg) }\end{array}$ \\
\hline Control & $25.60 \pm 0.56^{\mathrm{a}}$ & $17.23 \pm 0.57^{\mathrm{a}}$ & $11.54 \pm 0.38^{\mathrm{a}}$ \\
A. sativum & $14.12 \pm 0.65^{\mathrm{c}}$ & $12.58 \pm 0.68^{\mathrm{b}}$ & $6.41 \pm 0.35^{\mathrm{c}}$ \\
P. nigrum & $15.84 \pm 0.69^{\mathrm{c}}$ & $11.88 \pm 0.69^{\mathrm{b}}$ & $6.89 \pm 0.40^{\mathrm{c}}$ \\
G. glabra & $21.88 \pm 0.79^{\mathrm{b}}$ & $15.96 \pm 0.73^{\mathrm{a}}$ & $10.22 \pm 0.47^{\mathrm{b}}$ \\
\hline
\end{tabular}

Values in each column that characterized by different letters showed significant difference (Tukey test; $\mathrm{P}<0.05$ ).

$\pm 1{ }^{\circ} \mathrm{C}, 60 \pm 5 \%$ relative humidity $(\mathrm{RH})$ and photoperiod of 16:8 (L:D) $h$ and were reared on the larvae of flour moth (Ephestia kuehniella Zeller) as its laboratory host. During the rearing processes, the honey solution (10\%) was used for feeding of this biocontrol agent (Rafiee-Dastjerdi et al. 2008, 2009a, 2009b; Mahdavi 2013; Abedi et al. 2012, 2014; Asadi et al. 2018a).

\section{Demography of $\mathrm{H}$. hebetor}

For studying the demography of $H$. hebetor on its laboratory host, first one-hundred young female wasps (less than 24 $\mathrm{h}$ old) were exposed to sublethal concentration $\left(\mathrm{LC}_{30}\right)$ of each essential oil consist of $A$. sativum $(2.22 \mu \mathrm{l} / 1$ air), $P$. nigrum $(5.41 \mu \mathrm{l} / \mathrm{l}$ air) and G. glabra $(8.72 \mu \mathrm{l} / \mathrm{l}$ air $)$ on filter paper $(2 \times 2 \mathrm{~cm})$ in glass Petri dish with approximately volume of $60 \mathrm{ml}$. The selection of $\mathrm{LC}_{30}$ values for these testes was based on the results of earlier studies of IPM programs with synthetic and plant-derived compounds (Borzoui et al. 2016). This concentration $\left(\mathrm{LC}_{30}\right.$ ) was calculated from the analyses of bioassay experiments by using SPSS version 20 software. In the control experiments, the wasps were treated by distilled water. After $24 \mathrm{~h}$ of exposure, twenty-five live females randomly were selected and released singly to Petri dishes $(80 \mathrm{~mm}$ in diameter) and were paired with untreated males (less than $24 \mathrm{~h}$ old) (Ahmadpour 2017; Asadi et al. 2018a; Razmjou et al. 2018). The wasps were fed daily with honey solution (10\%) and seven larvae of E. kuehniella as host for oviposition. The biological features of the treated wasps (total 25 paired wasps) including survival and fecundity were recorded daily to death time of all treated females. Then, among deposited eggs by them, one-hundred eggs were selected randomly and the number of emerged larvae, pupae and adult wasps (male and female) were recorded. The life table of Carey (1993) that is the base of one-six life table analysis was used for studying the demography of this parasitoid wasp.

\section{Data analysis}

For statistical analysis, jackknife and pseudovalues were 
Table 2. The stable population parameters of $H$. hebetor females treated by the isolated essential oils.

\begin{tabular}{llllll}
\hline Treatment & GRR (female offspring) & $\mathbf{R}_{0}$ (female offspring) & $\boldsymbol{\lambda}$ (day $^{-1}$ ) & T (day) & DT (day) \\
\hline Control & $275.24 \pm 17.72^{\mathrm{a}}$ & $144.68 \pm 4.83^{\mathrm{a}}$ & $1.32 \pm 0.003^{\mathrm{a}}$ & $18.14 \pm 0.16^{\mathrm{b}}$ & $2.53^{\mathrm{a}} \pm 0.02^{\mathrm{c}}$ \\
A. sativum & $55.34 \pm 3.33^{\mathrm{c}}$ & $19.32 \pm 1.07^{\mathrm{d}}$ & $1.17 \pm 0.003^{\mathrm{d}}$ & $19.19 \pm 0.12^{\mathrm{a}}$ & $4.49 \pm 0.08^{\mathrm{a}}$ \\
P. nigrum & $90.38 \pm 6.01^{\mathrm{c}}$ & $40.96 \pm 2.39^{\mathrm{c}}$ & $1.23 \pm 0.004^{\mathrm{c}}$ & $17.93 \pm 0.13^{\mathrm{b}}$ & $3.34 \pm 0.05^{\mathrm{b}}$ \\
G. glabra & $182.48 \pm 10.70^{\mathrm{b}}$ & $88.51 \pm 4.05^{\mathrm{b}}$ & $1.30 \pm 0.004^{\mathrm{b}}$ & $17.10 \pm 0.12^{\mathrm{c}}$ & $2.64^{\mathrm{b}} \pm 0.03^{\mathrm{c}}$ \\
\hline
\end{tabular}

Values in each column that characterized by different letters showed significant difference (Tukey test; P < 0.05). GRR: Gross reproductive rate, R0: Net reproductive rate, $\lambda$ : Finite rate of increase, T: Mean generation time, DT: Doubling time

calculated for the control and each essential oil treatment and then the obtained pseudovalues were tested for normal distribution. The square-root and logarithmic transformations were performed on those parameters that had not normal distribution. Finally the normal data were analyzed by one-way ANOVA and the means were compared by Tukey test at probability level $(\mathrm{p}<0.05)$ by using SPSS version 20 software (Meyer et al. 1986; Maia et al. 2000).

\section{Results}

\section{Biological parameters}

The biological parameters from treated females of $H$. hebetor by three isolated essential oils are shown in Table 1. The shortest and longest females' longevity was obtained in A. sativum essential oil and the control, respectively $\left(\mathrm{F}_{3,96}\right.$ $=40.18, \mathrm{P}<0.05)$. The daily fecundity also significantly was affected by the tested essential oils; but, there was no significant difference between the control and G. glabra essential oil and also between the essential oils of $A$. sativum and $P$. nigrum $\left(\mathrm{F}_{3,96}=14.92, \mathrm{P}<0.05\right)$. Moreover, the lowest and highest daily fertility were observed in A. sativum essential oil (6.41 eggs) and the control (11.54 eggs), respectively $\left(\mathrm{F}_{3,96}=39.01, \mathrm{P}<0.05\right)$.

\section{Stable population parameters}

The stable population parameters from treated females of $H$. hebetor by the isolated essential oils are given in Table 2 . The gross reproductive rate (GRR) significantly was affected by the isolated essential oils, being the lowest in A. sativum essential oil and the highest in the control $\left(\mathrm{F}_{3,96}=82.01, \mathrm{P}<0.05\right)$. The $\mathrm{R}_{0}$ value in $A$. sativum essential oil (19.32 female offspring) was significantly lower than the control and the other essential oils $\left(\mathrm{F}_{3,96}=266.06, \mathrm{P}\right.$ $<0.05)$. The finite rate of increase $(\lambda)$ also varied under different essential oils treatments compared with the control. The lowest $\lambda$ value being in A. sativum essential oil and the highest was in the control $\left(\mathrm{F}_{3,96}=376.05, \mathrm{P}<\right.$ 0.05). Moreover, the shortest and longest values of mean generation time (T) were obtained in G. glabra and $A$. sativum essential oils, respectively $\left(\mathrm{F}_{3,96}=42.13, \mathrm{P}<0.05\right)$. In addition; the shortest and longest values of doubling time (DT) were seen in the control and A. sativum essential oil, respectively $\left(\mathrm{F}_{3,96}=296.77, \mathrm{P}<0.05\right)$.

\section{Population growth parameters}

The population growth parameters from treated females of $H$. hebetor by the isolated essential oils are shown in Table 3. About the intrinsic birth rate (b), there were no significant differences among the control, P. nigrum and G. glabra essential oils $\left(\mathrm{F}_{3,96}=234.28, \mathrm{P}<0.05\right)$. The highest intrinsic death rate (d) also was observed in P. nigrum essential oil that showed significant differences with the other essential oils $\left(\mathrm{F}_{3,96}=772.20, \mathrm{P}<0.05\right)$. The intrinsic rate of increase $\left(\mathrm{r}_{\mathrm{m}}\right)$ was strongly affected in offsprings of the treated females. The lowest $r_{\mathrm{m}}$ value was determined in the treated wasps of $H$. hebetor by A. sativum essential oil and the highest was in the control $\left(\mathrm{F}_{3,96}=381.23, \mathrm{P}<\right.$ $0.05)$. The gross hatch rate $\left(h_{x}\right)$ in A. sativum essential oil (0.51) was lower than the control and the other isolated

Table 3. The population growth parameters of $H$. hebetor females treated by the isolated essential oils.

\begin{tabular}{|c|c|c|c|c|c|}
\hline Treatment & Birth rate $\left(\right.$ day $\left.^{-1}\right)$ & Death rate $\left(\right.$ day $\left.^{-1}\right)$ & $r_{m}\left(\right.$ day $\left.^{-1}\right)$ & Hatch rate $(\%)$ & Sex ratio $(\%)$ \\
\hline Control & $0.38 \pm 0.003^{a}$ & $0.11 \pm 0.001^{c}$ & $0.27 \pm 0.002^{a}$ & 0.67 & 0.63 \\
\hline A. sativum & $0.26 \pm 0.003^{b}$ & $0.11 \pm 0.001^{c}$ & $0.15 \pm 0.003^{d}$ & 0.51 & 0.34 \\
\hline P. nigrum & $0.39 \pm 0.005^{a}$ & $0.18 \pm 0.002^{a}$ & $0.21 \pm 0.003^{c}$ & 0.58 & 0.56 \\
\hline G. glabra & $0.38 \pm 0.003^{a}$ & $0.12 \pm 0.001^{b}$ & $0.26 \pm 0.003^{b}$ & 0.64 & 0.57 \\
\hline
\end{tabular}

Values in each column that characterized by different letters showed significant difference (Tukey test; $\mathrm{P}<0.05)$. rm: Intrinsic rate of increase 
Asadi et al.

Table 4. The reproductive parameters of $H$. hebetor females treated by the isolated essential oils.

\begin{tabular}{lllll}
\hline Treatment & Gross fertility rate (egg) & Net fertility rate (egg) & Gross fecundity rate (egg) & Net fecundity rate (egg) \\
\hline Control & $292.72 \pm 18.84^{\mathrm{a}}$ & $152.80 \pm 5.07^{\mathrm{a}}$ & $436.90 \pm 28.12^{\mathrm{a}}$ & $228.06 \pm 7.56^{\mathrm{a}}$ \\
A. sativum & $83.01 \pm 5.00^{\mathrm{c}}$ & $27.94 \pm 1.52^{\mathrm{d}}$ & $162.77 \pm 9.81^{\mathrm{c}}$ & $54.78 \pm 2.98^{\mathrm{c}}$ \\
P. nigrum & $93.60 \pm 6.23^{\mathrm{c}}$ & $41.60 \pm 2.41^{\mathrm{c}}$ & $161.39 \pm 10.74^{\mathrm{c}}$ & $71.72 \pm 4.15^{\mathrm{c}}$ \\
G. glabra & $204.89 \pm 12.01^{\mathrm{b}}$ & $97.95 \pm 4.47^{\mathrm{b}}$ & $320.14 \pm 18.77^{\mathrm{b}}$ & $153.05 \pm 6.99^{\mathrm{b}}$ \\
\hline
\end{tabular}

Values in each column that characterized by different letters showed significant difference (Tukey test; $\mathrm{P}<0.05$ ).

essential oils. Also, the offspring sex ratio $\left(\mathrm{S}_{\mathrm{x}}\right)$ value based on the number of emerged females on total number of emerged male and female wasps was affected in offsprings of $H$. hebetor; indicating that $A$. sativum essential oil significantly have decreased the emergence of female offspring in $H$. hebetor.

\section{Reproductive parameters}

The reproductive parameters from treated wasps of $H$. hebetor by the isolated essential oils are given in Table 4 . The lowest and highest gross fertility rate were determined in A. sativum essential oil and the control and the difference between $A$. sativum and $P$. nigrum essential oil wasn't significant $\left(\mathrm{F}_{3,96}=70.26, \mathrm{P}<0.05\right)$. The net fertility rate also significantly was lower in A. sativum essential oil than the control and the other essential oils $\left(\mathrm{F}_{3,96}=243.17\right.$, $\mathrm{P}<0.05)$. Moreover, the results of gross fecundity rate indicated that there was no significant difference between A. sativum and $P$. nigrum essential oils $\left(\mathrm{F}_{3,96}=52.82, \mathrm{P}<\right.$ $0.05)$. In addition, the net fecundity rate showed significant differences among the control and the essential oils treatments $\left(\mathrm{F}_{3,96}=193.41, \mathrm{P}<0.05\right)$.

\section{Discussion}

The demographic parameters based on the demographic toxicology are very useful tools for studying the responses of different insects to any synthetic or natural compounds (Forbes and Calow 1999). The sublethal results showed that application of the isolated essential oils negatively have changed the biological parameters of $H$. hebetor including the adult longevity, daily fecundity and daily fertility. Similar observations were reported by Seyyedi (2011), Hashemi et al. (2014) Ahmadpour (2017), Asadi et al. (2018a) and Razmjou et al. (2018).

In our study, the sublethal concentration of A. sativum essential oil caused the most significant negative effects on the above-mentioned parameters; while, G. glabra essential oil induced the less negative effects. The obtained values from reproductive parameters in the treated females of $H$. hebetor including the net and gross fecundity and fertility rates were in agreement with the results reported earlier. According to the results of Ahmadpour (2017) and Razmjou et al. (2018), F. vulgare and C. carvi essential oils showed the most and A. millefolium and $H$. persicum essential oils caused the lowest adverse effects on these parameters, respectively. In another study, Asadi et al. (2018a) found that concerning these parameters $R$. officinalis and $S$. officinalis showed the highest and lowest negative effects, respectively.

In our study there were significant differences on the stable population parameters in the treated wasps of $H$. hebetor. The lowest female fecundity in A. sativum essential oil caused the lowest gross (GRR) and net reproductive $\left(\mathrm{R}_{0}\right)$ rates among three examined essential oils. The net reproductive rate in all treatments was significantly lower than the gross reproductive rate indicating that the survival rate $\left(l_{x}\right)$ was negatively affected by the isolated essential oils. The longest mean generation time was observed after $A$. sativum essential oil treatment. Hashemi et al. (2014), Ahmadpour (2017); Asadi et al. (2018a) and Razmjou et al. (2018) concluded that F. assafoetida, $F$. vulgare, $R$. officinalis and C. carvi essential oils showed the substantially negative effects on the gross and net reproductive rates, finite rate of increase, mean generation and doubling time of $H$. hebetor. In our investigation G. glabra essential oil caused the lowest adverse effects on these parameters.

This research showed that the tested essential oils had negative sublethal effects on $H$. hebetor. Among the different demographic parameters, the intrinsic rate of increase $\left(\mathrm{r}_{\mathrm{m}}\right)$ is the most important parameter for evaluating the total effect of different compounds on insect populations. Hashemi et al. (2014), Ahmadpour (2017); Asadi et al. (2018a) and Razmjou et al. (2018) stated that $\mathrm{r}_{\mathrm{m}}$ value of $H$. hebetor under all examined essential oils decreased compared with the control. At the same time, our findings indicated that G. glabra essential oil has the less negative effects and is relatively safe on $H$. hebetor. It means that this essential oil can be recommended as a suitable plant-derived compound on $H$. hebetor containing IPM approaches. 


\section{Acknowledgement}

This research was supported by University of Mohaghegh Ardabili (Ardabil, Iran), under grant number [95/15/18581].

\section{References}

Abedi Z, Saber M, Gharekhani G, Mehrvar A, Mahdavi V (2012) Effects of azadirachtin, cypermethrin, methoxyfenozide and pyridalil on functional response of Habrobracon hebetor Say (Hymenoptera: Braconidae). J Plant Prot Res 52(3):353-358.

Abedi Z, Saber M, Gharekhani G, Mehrvar A, Kamita SG (2014) Lethal and sublethal effects of azadirachtin and cypermethrin on Habrobracon hebetor Say (Hymenoptera: Braconidae). J Econ Entomol 107:638-645.

Abramson CI, Wanderley PA, Wanderley MJA, Mina AJS, De Souza OB (2006) Effect of essential oil from citronella and alfazema on fennel aphids Hyadaphis foeniculi Passerini (Hemiptera: Aphididae) and its predator Cycloneda sanguinea L. (Coleoptera: Coccinellidae). American J Environ Sci 3(1):9-10.

Ahmadpour R (2017) The effects of isolated essential oils from four medicinal plants on the ectoparasitoid wasp, Habrobracon hebetor Say. under laboratory conditions. M.Sc. Thesis. University of Mohaghegh Ardabili, Ardabil, Iran.

Ajayi FA, Olonisakin A (2011) Bioactivity of three essential oils extracted formidable seeds on the rust-red flour beetle Tribolium castaneum (Herbest) infesting stored pearl millet. Trakia J Sci 9(1):28-36.

Asadi M, Nouri-Ganbalani G, Rafiee-Dastjerdi H, Hassanpour M, Naseri B (2018a) The effects of Rosmarinus officinalis L. and Salvia officinalis L. (Lamiaceae) essential oils on demographic parameters of Habrobracon hebetor Say (Hym.: Braconidae) on Ephestia kuehniella Zeller (Lep.: Pyralidae) Larvae. J Essent Oil Bear Plants 21(3):713-731.

Asadi M, Rafiee-Dastjerdi H, Nouri-Ganbalani G, Naseri B, Hassanpour M (2018b) The effects of plant essential oils on the functional response of Habrobracon hebetor Say (Hymenoptera: Braconidae) to its host. ISJ 15:169-182.

Banks JE, Stark JD (1998) What is ecotoxicology? An ad-hoc grab bag or an interdisciplinary science? Integr Bio1 (5):195-204.

Bakkali F, Averbeck S, Averbeck D, Idomar M (2008) Biological effects of essential oils. Food Chem Toxic 46:446-475.

Borzoui E, Naseri B, Abedi Z, Karimi-Pormehr MS (2016) Lethal and sublethal effects of essential oils from Artemisia khorassanica and Vitex pseudo-negundo against Plodia interpunctella (Lepidoptera: Pyralidae). Environ Entomol 45(5):1220-1226.

Carey JR (1993) Applied Demography for Biologists with
Special Emphasis on Insects. Oxford University Press, New York.

Croft BA (1990) Arthropod Biological Control Agents and Pesticides. John Wiley and Sons, New York.

Dent D (1995) Integrated Pest Management. Chapman and Hall, London.

Desneux N, Decourtye A, Delpuech JM (2007) The sublethal effects of pesticides on beneficial arthropods. Annu Rev Entomol 52:81-106.

Forbes VE, Calow P (1999) Is the per capita rate of increase a good measurement of population level-effect of in ecotoxicology? Environ Toxic Chem 18:1544-1556.

Gerling D (1971) Occurrence, abundance and efficiency of some local parasitoids attacking Spodoptera littoralis (Lepidoptera: Noctuidae) in selected cotton fields in Israel. Ann Entomol Soc Am 64:492-499.

Hamedi N, Fathipour Y, Saber M (2010) Sublethal effects of fenpyroximate on life table parameters of the predatory mite Phytoseius plumifer. BioControl 55:271-278.

Hamedi N, Fathipour Y, Saber M (2011) Sublethal effects of abamectin on the biological performance of the predatory mite, Phytoseius plumifer (Canestrini \& Fanzago) (Acari: Phytoseiidae). Exper Appl Acar 53:29-40.

Hashemi Z, Goldansaz H, Hosseini-Naveh V (2014) Effects of essential oil of Ferula assafoetida L. on biological parameters of the parasitoid wasp, Habrobracon hebetor (Hym.: Braconidae) under laboratory conditions. Proceedings $21^{\text {th }}$ Iranian Plant Protection Congress, 9-13 September, University of Urmia, Iran.

Isman MB (2000) Plant essential oils for pest and disease management. Crop Prot 19:603-608.

Isman MB, Wilson JA, Bradbury F (2008) Insecticidal activities of commercial rosemary oils (Rosmarinus officinalis) against larvae of Pseudaletia unipunctata and Trichoplusia $n i$ in relation to their chemical compositions. Pharma Biol 46(1-2):82-87.

Kramer S, Gvozdic V (2016) Field studies of the efficacy of some commercially available essential oils against horse flies (Diptera: Tabanidae). Entomol General 36(2):97-105.

Koul O, Walia S, Dhaliwal GS (2008) Essential oils as green pesticides: potential and constraints. Biopest Inter 4(1):63-84

Magro SR, Parra JRP (2001) Biologia do ectoparasitoide Bracon hebetor Say (Hymenoptera: Braconidae) em sete especies de lepidopteros. Sci Agr 58:693-698.

Mahdavi V (2013) Residual toxicity of some pesticides on the larval ectoparasitoid Habrobracon hebetor Say (Hymenoptera: Braconidae). J Plant Prot Res 53:27-32.

Mahmoudvand M, Abbasipour H, Basij M, Hosseinpour MH, Rastegar F, Nasiri MB (2011) Fumigant toxicity of some essential oils on adults of some stored-products pests. Chil J Agric Res 71(1):83-89. 
Maia AHN, Alferdo JBL, Campanhola C (2000) Statistical inference on associated fecundity life table parameters using jackknife technique: computational aspects. J Econ Entomol 93:511-518.

Manzoor F, Nasim G, Saif S, Malik SA (2011) Effect of ethanolic plant extracts on three storage green pests of economic importance. Pakistan J Biotech 43(6):2941-2946.

Meyer JS, Ingersoll CG, Mac Donald LL, Boyce MS (1986) Estimating uncertainty in population growth: jackknifes vs. bootstrap techniques. Ecol 67:1156-1166.

Motazedian N, Ravan S, Bandani AR (2012) Toxicity and repellency effects of three essential oils against Tetranychus urticae Koch (Acari: Tetranychidae). J Agri Sci Tech 14:275-284.

Mwine J, Ssekyewa C, Kalanzi K, Van Damme P (2013) Evaluation of selected pesticidal plant extracts against major cabbage insect pests in the field. J Medic Plant Res 7(22):1580-1586.

Navaei AN, Taghizadeh M, Javanmoghaddam H, Oskoo T, Attaran MR (2002) Proceedings of $15^{\text {th }}$ Iranian Plant Protection Congress 7-11 September, Razi University, Kermanshah, Iran.

Rafiee-Dastjerdi H, Hejazi MJ, Nouri-Ganbalani G, Saber M (2008) Toxicity of some biorational and conventional insecticides to cotton bollworm, Helicoverpa armigera (Lepidoptera: Noctuidae) and its ectoparasitoid, Habrobracon hebetor Say (Hymenoptera: Braconidae). J Entomol Soc Iran 28(1):27-37.

Rafiee-Dastjerdi H, Hejazi MJ, Nouri-Ganbalani G, Saber M (2009a) Sublethal effects of some biorational and conventional insecticides on ectoparasitoid, Habrobracon hebetor Say (Hymenoptera: Braconidae). J Entomol Soc Iran 6(2):82-89.

Rafiee-Dastjerdi H, Hejazi MJ, Nouri-Ganbalani G, Saber M (2009b) Effects of some insecticides on functional response of ectoparasitoid, Habrobracon hebetor Say (Hymenoptera: Braconidae).J Entomol Soc Iran 6(3):161-166.

Rafiee-Dastjerdi H, Khorrami F, Razmjou J, Esmaielpour B, Golizadeh A, Hassanpour M (2013) The efficacy of some medicinal plant extracts and essential oils against potato tuber moth, Phthorimaea operculella (Zeller) (Lepidoptera: Gelechiidae). J Crop Prot 2(1):93-99.

Razmjou J, Mahdavi V, Rafiee-Dastjerdi H, Farhoomand A, Molapour S (2018) Insecticidal activities of some essential oils against larval ectoparasitoid, Habrobracon hebetor Say (Hymenoptera: Braconidae). J Crop Prot 7(2):151-159.

Sagheer M, Hassan M, Najam-ul-Hassan M, Farhan M, Ahmad Khan FZ, Rahman A (2014) Repellent effects of selected medicinal plant extracts against rust-red flour beetle, Tribolium castaneum (Herbst) (Coleoptera: Tenebrionidae). J Entomol Zool Stud 2(3):107-110.
Salerno G, Colazza S, Conti E (2002) Sublethal effects of deltamethrin on walking behavior and response to host kairomone of egg parasitoid, Trissolcus basalis. Pest Manag Sci 58:663-668.

Seyyedi A (2011) Insecticidal effects of Ferula gummosa L. on Ephestia kuehniella Zeller and its parasitoid wasp, Habrobracon hebetor Say. M.Sc. thesis. University of Shahed, Tehran, Iran.

Shiva Parsia A, Valizadegan O (2015) Fumigant toxicity and repellent effect of three Iranian eucalyptus species against the lesser grain beetle, Rhyzopertha dominica (F.) (Col.: Bostrychidae). J Entomol Zool Stud 3(2):198-202.

Stark JD, Wennergren U (1995) Can population effects of pesticides be predicted from demographic toxicological studies? J Econ Entomol 88:1089-1096.

Stark JD, Banks E (2003) Population level effects of pesticides and other toxicants on arthropods. Annu Rev Entomol 48:505-519.

Stark JD, Banks E, Acheampong S (2004) Estimating susceptibility of biological control agents to pesticides: influence of life history strategies and population structure. Biol Cont 29:392-398.

Stapel JO, Cortesero AM, Lewis WJ (2000) Disruptive sublethal effects of insecticides on biological control: altered foraging ability and life span of a parasitoid after feeding on extrafloral nectar of cotton treated with systemic insecticides. BioControl 17:243-249.

Walthall WK, Stark JD (1996) A comparison of acute mortality and population growth rate as endpoints of toxicological effect. Ecotoxic Environ Safe 37:45-52.

Yazdgerdian AR, Akhtar Y, Isman MB (2015) Insecticidal effects of essential oils against woolly beech aphid, Phyllaphis fagi (Hemiptera: Aphididae) and rice weevil, Sitophilus oryzae (Coleoptera: Curculionidae). J Entomol Zool Stud 3(3):265-271.

Yildirim E, Kordali S, Yazici G (2011) Insecticidal effects of essential oils of eleven plant species from Lamiaceae on Sitophilus granarius (L.) (Coleoptera: Curculionidae). Romani Biotech Let 16(6):6702-6709.

Youm O, Gilstrap FE (1993) Life-fertility tables of Bracon hebetor Say (Hymenoptera: Braconidae) reared on Heliocheilus albipunctella de Joannis (Lepidoptera: Noctuidae). Int J Trop Insect Sci 14(4):455-459. 